\title{
Exposure, timing, and vulnerability: The role of public transport in inducing gentrification
}

\author{
Malithi Fernando (corresponding author) \\ International Transport Forum, OECD ${ }^{1}$ \\ malithi.fernando@itf-oecd.org
}

\section{Daniel Johnson}

Institute for Transport Studies, University of Leeds

\author{
Eva Heinen \\ Institute for Transport Studies, University of \\ Leeds
}

\begin{abstract}
Gentrification is an increasingly common phenomenon in many urban neighbourhoods. While cities invest in more sustainable travel options for their residents, there is limited literature on its connection to gentrification of the surrounding areas. Understanding whether these investments induce gentrification is essential to ensure the positive impacts of public transport are not undermined by the displacement it may create. This paper presents a multi-analysis approach to studying gentrification, defined by a bi-axial definition of neighbourhood change which considers the negative components (displacement) and positive components (neighbourhood upgrading) of gentrification. We focus specifically on the extent to which exposure to public transport induces gentrification-like changes in neighbouring communities, the influence of time on the kind and magnitude of changes, and whether disinvested communities are most vulnerable. We analyse neighbourhood changes in Manchester, UK, in response to the introduction of the Metrolink tram network, and conclude that there is evidence of gentrification in areas with access to new light rail. We conclude that the length of exposure has a significant impact on the magnitude and direction of change for certain indicators of gentrification. We find mixed results regarding the susceptibility of disinvested communities to gentrification.
\end{abstract}

\section{Article history:}

Received: September 20, 2020

Received in revised form: February 25,2021

Accepted: March 252021

Available online: August 12, 2021

\section{Introduction}

The current wave of urbanisation is the largest in global history. Developed nations are estimated to host $88 \%$ of its citizens in cities by 2050 (United Nations Department of Economic and Social Affairs Population Division, 2019). Urbanisation comes with challenges of overcrowding, greater environmental pressure, increased costs for housing and longer travel times. At the same time, public awareness of climate change is heightened and cities are looking to provide sustainable travel options for their growing populations. Shifting from the car-centric planning of the previous generation and enhancing public transport offerings becomes a clear mandate.

\footnotetext{
${ }^{1}$ Research conducted while at the Institute for Transport Studies, University of Leeds.

Copyright 2021 Malithi Fernando, Eva Heinen, \& Daniel Johnson

http://dx.doi.org/10.5198/jtlu.2021.1897

ISSN: 1938-7849 | Licensed under the Creative Commons Attribution - Noncommercial License 4.0
}

The Journal of Transport and Land Use is the official journal of the World Society for Transport and Land Use (WSTLUR) and is published and sponsored by the University of Minnesota Center for Transportation Studies. 
Investing in public transport has strong social as well as environmental motivations. To fully participate in society, individuals need access to jobs, education, services and social connection (Lucas, Philips, Mulley, and Ma, 2018; Markovich and Lucas, 2011; Social Exclusion Unit, 2003). Young people and the elderly are especially vulnerable to these barriers to economic participation and social isolation (Dobbs, 2005; Lucas, 2012; Social Exclusion Unit, 2003). With a strong correlation between social exclusion and a lack of transport access, the solution seems quite clear: invest in public transport.

Studies of public transport investments in deprived communities have reported significant improvements in patronage, travel uptake, and secondary benefits related to employment, educational opportunities and healthcare visits, when coupled with complementary policies and land-use plans (Lucas, 2012; Lucas et al., 2008; Mejia-Dorantes and Lucas, 2014). Using 2011 UK Census data, Johnson, Ercolani, and Mackie (2017) show that shorter public transport times are also associated with higher levels of employment. Light rail transit (LRT), more than tire-based systems, encourages transit-oriented development (TOD), sustainable neighbourhood improvements, economic investment and the widening of job markets (Cervero, 1984; Knowles and Ferbrache, 2016; Rodríguez and Targa, 2004; Soursourian, 2010). As more cities turn to light rail transport systems, it is crucial that the influence of these networks on residents is better understood.

Transport project appraisal often evaluates the distributional benefits of these expected improvements to disadvantaged groups. While the positive outcomes of gaining access to public transport is supported in the literature, there is little focus in previous work on whether the intended populations are experiencing these benefits. If disadvantaged populations are displaced due to market factors which also respond to neighbourhood improvements and new public transport investment, then the anticipated downstream positive impacts may not correspond with reality.

Gentrification refers to this complex set of social and economic changes in neighbourhoods which are increasingly observed in cities. We define gentrification as the combination of neighbourhood upgrading and displacement in disinvested neighbourhoods, occurring at a more pronounced rate than the overall metropolitan region.

There is a small but growing body of academic literature on the role of public transport investment acting as a catalyst for gentrification (see Baker and Lee, 2019; Barton and Gibbons, 2017; Chapple et al, 2017b; Dong, 2017; Grube-Cavers and Patterson, 2015; Kahn, 2007; Pollack, Bluestone, and Billingham, 2010; Rérat and Lees, 2010). However, gentrification literature suffers from definitional and methodological disparities, making the results of various studies, governed by different theories, methods, and data, difficult to compare. For example, multi-city studies in Canada and the US, all employing different methods and different operational definitions, find that the relationship between public transport and gentrification is strong in some cities yet not apparent in others (Baker and Lee, 2019; Grube-Cavers and Patterson, 2015). Dong (2017) and Chapple et al. (2017b) both deem their results are inconclusive and do not find strong evidence of gentrification due to public transport access in Portland, USA and the San Francisco Bay Area, respectively.

Thus, despite an increased awareness of the role that transport investments may play in gentrification, the extent and way it impacts communities is not well understood (Zuk, et al. 2018). Moreover, most research has taken place in North America, so there is need to understand the impacts of public transport on neighbourhoods in other geopolitical contexts.

This paper examines the impact of investment in new LRT infrastructure on gentrification, adding to the limited UK research in the field by adopting a more nuanced definition of gentrification, triangulating its effects using multiple methods, and investigating the relationship between gentrification and length of exposure to LRT. More specifically, we study the impacts of the introduction of the Metrolink tram network in Manchester, UK, over time. We use a biaxial definition, which considers 
both resident displacement and neighbourhood upgrading effects of gentrification and adopt a multianalysis approach using publicly available data sources to determine whether our findings are sensitive to methodology.

Particularly, we aim to answer:

1) To what extent does exposure to new public transport infrastructure lead to gentrification?

2) To what extent does length of exposure influence gentrification-like changes?

3) To what extent are disinvested areas more susceptible to gentrification-like changes?

\section{Literature review}

To understand the potential impact of transport investments on gentrification, it is important to first gain an appreciation for the concept of gentrification and develop our operational definition.

\subsection{Theories of gentrification}

First coined by Glass (1964) to describe the influx of gentry into lower-income neighbourhoods in London, gentrification is used to describe a host of neighbourhood changes with little consensus on its actual definition. Zuk et al. (2018, p. 32) synthesise their review of the disparate body of gentrification literature by concluding that "depending on the time and place, gentrification has been seen as a tool, goal, outcome or unintended consequence of the revitalisation process."

Gentrification can be seen either as a process or event. For example, Melchert and Naroff (1987) consider gentrification to unfold over a series of phases in their predictive model, while Grube-Cavers and Patterson (2015) maintain that gentrification is a discrete event. Both assumptions dictate the type of analysis undertaken by the respective studies. Regardless of discrepancies in modality, there is consensus that gentrification involves localised change. The nature of these changes differs by theory, as scholars asymmetrically stress spatial, economic, physical, or demographic change. Existing literature discusses themes of location, real estate, facilitators, in-movers, opportunities, and displacement concerning gentrification.

Locations susceptible to gentrification are typically areas of historic disinvestment and decline, a pattern found most predominantly in lower-income, inner-city neighbourhoods (Hamnett, 1991; Hyra, 2014; Lees, 2000, 2003; Zuk et al., 2018, 2015). While gentrification-like changes are possible in affluent communities, the social impacts of gentrification on vulnerable neighbourhoods are more salient. Independent of the exact location, areas susceptible to gentrification typically have relatively affordable housing stock, with high renovation potential. The supply side of gentrification is described by the rent gap theory postulated by Smith (1987) which refers to the economic gap between the current land value and its potential value with a different use.

The changing narrative around urban versus suburban living in the last few decades has enhanced the comparative appeal of an inner-city lifestyle. The demand for revitalised inner-city neighbourhoods increases as the middle-class seek the urban amenities offered by proximity to employment, recreation, cultural and commercial districts, and lower (but appreciating) house prices (Ley, 1986; Zuk et al., 2018). The studies that portray gentrification as a series of waves, partially differentiate waves based on the amenities they prioritise. First-wave gentrifiers, typically of lower-income but higher educational attainment, move in driven by affordability and the desire for ethnically and class diverse neighbourhoods (Lees, Slater, and Wyly, 2013; Melchert and Naroff, 1987). Keddie (2014) finds examples of early gentrifiers lobbying for affordable housing to counteract the negative consequences they feel responsible for. After negative social conditions and crime are stabilised (or perceived as such), a second wave of higher-income professionals move into central neighbourhoods, threatening the early gentrifiers' sense 
of social ideals (Ellen et al., 2017; Keddie, 2014; Lees, 2003).

Facilitators catalyse the gentrification process by linking the supply side of disinvested neighbourhoods and depreciated housing with the demand from in-movers (or gentrifiers). Developers, mortgage lenders, and government agencies from local to federal jurisdictions play a role in creating regeneration policies, funding, planning, and constructing projects which encourage gentrification (Zuk et al., 2018).

Most scholars agree that gentrification is characterised by a demographic shift (see Atkinson, 2000; Grube-Cavers and Patterson, 2015; Ley, 1986; Zuk et al., 2018; Zuk and Chapple, 2015). Gentrifiers move into neighbourhoods of typically lower-income incumbent residents with high proportions of minority groups and elderly citizens. The in-moving population is disproportionately young, white, professionals with higher levels of education and income (Hamnett, 1991; Marcuse, 1985; Zuk et al., 2018).

This demographic shift is often partnered with displacement, but how different studies treat the phenomenon varies. Baker and Lee (2019) propose that displacement is inherently part of gentrification, rather than an outcome of the process, while Zuk et al. (2018) advocates for differentiating between the two. The results of most work, whether calling for distinction or integration, include displacement as a key component or result of gentrification. The variation in opinion comes from a lack of consensus in its definition. In this paper we adopt a definition consistent with Clay (1979) who terms gentrification without displacement as incumbent upgrading.

\subsection{Defining gentrification}

In this study, we define gentrification as the combination of neighbourhood upgrading and displacement in disinvested neighbourhoods, occurring at a more pronounced rate than the overall metropolitan region. Our operational definition is consistent with the dominant themes described above and combines the strengths of previous definitions of gentrification to establish a more nuanced framework to guide our methods and analysis. We particularly highlight the observations made by Marcuse (1985) noting that the gentrifiers and the gentrified are demographically distinct, and the process of gentrification occurs in a spatially concentrated manner at a rate of change that exceeds the surrounding region.

More recently, Baker and Lee (2019) classify changes associated with gentrification into two categories: gentrification and TOD. We agree that considering the positive and negative dimensions of gentrification is crucial. We propose, however, that labelling the positive changes as TOD implies that TOD solely benefits neighbourhoods and using gentrification as a measure of negative change flattens the multidimensionality of gentrification. TOD is often how gentrification is realised; it is responsible for the same benefits and consequences (Dong, 2017).

This study opts to group the positive impacts of TOD and gentrification as neighbourhood upgrading and the negative consequences as displacement. Neighbourhood upgrading includes the positive changes envisioned when cities initiate revitalisation projects: improvements in urban realm, sustainable travel, crime, and road safety. Displacement refers to the shift of working-class residents out of an area, with a simultaneous influx of middle-class professionals. Both these types of changes occur at a more pronounced rate in gentrifying neighbourhoods, than the overall metropolitan region.

Viewing gentrification as a two-pronged neighbourhood change maintains the distinction between incumbent upgrading and gentrification made by Clay (1979). The former is an ideal revitalisation scenario for existing residents (neighbourhood upgrading without displacement), and the latter includes both upgrading and displacement.

\subsection{Influence of public transport}

Public transport, and more specifically LRT, is generally seen as a positive feature of a neighbour- 
hood. Even individuals not dependent on public transport consider it a neighbourhood amenity. In wealthier neighbourhoods with high car ownership, the option value of public transport remains high; people are willing to pay to maintain the option to use public transport (Pollack et al., 2010).

If access to public transport is valuable, its market impact on property prices is only to be expected. While variation in housing type, the quality of service of the public transport system, and the TOD effects of public transport developments all influence the level of uplift (Wardrip, 2011), the general impact is an increase in housing prices. Knaap, Ding, and Hopkins (2001) observe that even before the infrastructure is built, expansion plans can lead to prospective price inflation and the displacement of existing renters.

If households are displaced from public transport-rich areas, it follows that their new residential locations will have poorer public transport access. Locations of desired services and destinations also change as neighbourhoods transform to serve a new demographic of residents, requiring remaining incumbent residents to travel more than previously (Chapple et al., 2017a). These impacts reflect the three-fold framework of social exclusion by Church, Frost, and Sullivan (2000). It categorises contributing factors as related to origin (household) location, destinations (services, jobs, facilities etc.), and the available public transport services between the two.

The conversations around quantitative economic benefits of land value uplifts eclipse the more nebulous social impacts on the people living in these neighbourhoods (Baker and Lee, 2019; Zuk et al., 2018). The disparity is understandable given that land value capture is a funding alternative for projects ${ }^{2}$. The data required for such analysis, such as property transaction information, is also easier to obtain than the data on changes in sociodemographics, land use, and households that inform thorough social impact analyses.

\section{$2.4 \quad$ LRT and gentrification}

Existing research on the impacts of LRT on gentrification vary in methods, data, and definitions similar to the broader gentrification literature. Their conclusions are, therefore, difficult to compare.

Some studies use a limited number of variables to establish patterns of public transport induced gentrification. Generally, they seem to imply that light rail is linked to characteristics of gentrification. For example, metro access was found to be one of the five leading predictors of gentrification by Turner (2001) in their Washington DC study looking at housing sales above the city average. In a study of fourteen US cities, Kahn (2007) and finds a disproportionate increase in property values and education levels in census tracts adjacent to public transport stations, but the linear regression results are heterogeneous between different urban areas. Pollack et al. (2010) find rent, income, and vehicle ownership are higher in areas with greater public transport access using data from a dozen US cities, and that neighbourhoods with higher proportions of renters are more susceptible. Barton and Gibbons (2017) conclude that while proximity to subway stations has a significant impact on income changes, it is secondary to other factors. These studies, while establishing interesting patterns between LRT access and some sociodemographic variables, do not yet offer a fully comprehensive understanding of gentrification, due to their relatively narrow definition and scope.

More complex work captures multiple dimensions of change through combined indicators such as income, race and education, as well as housing values, rent, and proxies for revitalization. Baker and Lee (2019) incorporate many of these variables in their fourteen-city US study and find a lack of consistent evidence for gentrification; neighbourhood change effects are highly varied between cities. They do find that gentrifiable (or disinvested) areas experience greater changes with respect to gentrification as a result of light rail access. Grube-Cavers and Patterson (2015) assert a stronger connection between rapid rail transport and gentrification in their Canadian study applying survival analysis techniques. They con-

${ }^{2}$ Land value capture seeks to monetise the windfall gains achieved by landowners in proximity to a new public transport intervention to help pay for the intervention itself (Medda, 2012; Transport for London, 2017). 
clude that gentrification, is significantly related to proximity to LRT, as defined by the performance of demographic and socioeconomic variables in two of three study cities.

Like Baker and Lee (2019), their findings show that gentrification responses to LRT vary by urban area. Grube-Cavers and Patterson (2015) restrict analysis only to gentrifiable areas which have lower average incomes and lower education levels at the start of the study period, unlike Baker and Lee (2019) who include all areas but conclude that disinvested areas are more susceptible to gentrification. While Grube-Cavers and Patterson (2015) assert that gentrification occurs in gentrifiable communities, Baker and Lee (2015) are able to demonstrate this by comparing outcomes between gentrifiable communities and those that are more affluent. We consider that the latter offers a stronger contribution with respect to the impact of gentrifiable-ness.

Few studies have found very conclusive findings. Chapple et al. (2017b) shows that among multiple socioeconomic, locational and built environment variables, rail access in the San Francisco Bay Area is a predictor of gentrification. In a unique study combining primary data from questionnaires with secondary sociodemographic datasets, Rérat and Lees (2010) find that proximity and transport connectivity are valued much higher than other neighbourhood amenities when choosing residential location by Swiss gentrifiers. This adds a dimension often absent from studies using secondary data. Despite these insights, all studies acknowledge that individually, they provide an incomplete picture of neighbourhood changes.

\section{$3 \quad$ Methodology}

\subsection{Study setting: Geography and timeline}

Greater Manchester (GM) is the second largest conurbation of Great Britain with over 2.5 million inhabitants. The urban area consists of multiple smaller local centres. Manchester's Metrolink (Figure 1) is the largest light rail network in the UK, and the largest public transport investment outside of London. The network was built in three phases. Phase 1 opened in 1992 and includes service to relatively affluent areas of Manchester. Phase 2 opened in 2001. Phase 3 (in reality, split into two phases) was built between 2011 and 2014. This final phase serves several less-affluent communities.

We focus on the 2011 to 2017 time period, from before Phase 3 was built to after it was completed in 2014. We prioritise including Phase 3 in this study, despite some data limitations (see Section 3.3), because it serves less-affluent communities that may be more susceptible to displacement and gentrification pressures. Phase $1 \& 2$ are also included in the analysis to investigate the influence of gentrification over time. This allows us to differentiate between the impacts of long term and short-term exposure to public transport.

\subsection{Unit of analysis}

Our analyses are based on the 2011 Lower Layer Super Output Areas (LSOA). Greater Manchester is divided into 1673 LSOAs. This level of granularity highlights changes at the neighbourhood level while still being large enough to obtain adequate data. Data available in other spatial units were converted to LSOAs. For example, income estimates were derived from Middle Layer Super Output Areas (MSOA). MSOAs are aggregations of LSOAs, therefore there are no instances in the study area where an LSOA is associated with more than one. 


\subsection{Data}

We selected variables based on our literature review (Section 2). While longitudinal records of socioeconomic, property, and locational data from individuals before and after an intervention are ideal for establishing changes and causal patterns, such information is rarely publicly available. In the absence of such datasets, we use LSOA-level panel data (repeated observations over time of the same spatial unit) from the beginning and end of the study period. We compiled a robust data timeline as an initial step in the study to highlight gaps in data and inform the methods used for analysis. Census data is not viable for gentrification variables, which observe the change in a neighbourhood characteristic between 2011 and 2017 because the latest UK Census at the time of study was completed in 2011. Instead, we use multiple public data sets which align with the timeline of the tram network development to inform study variables. The 2011 Census is used to determine the propensity to gentrify (PTG) of each LSOA in 2011 (Section 3.6). Table 1 summarises our data sources.

\subsection{Exposure to public transport}

Exposure to new public transport is determined by a buffer measure of exposure, based on the Euclidean distance between Metrolink stations and the population-weighted centroids of the LSOAs. LSOAs are considered exposed to public transport if their centroids are located within 1000 metres of a station. If all stations are greater than 1000 metres away, then the LSOA is not exposed. The urban LSOAs surrounding tram stations are sufficiently small for this measure to be representative of station access. The Euclidean distances are used for their computational simplicity and because the straight-line distance has been shown to be as, if not more, influential on property values than network distances (Hess and Almeida, 2007). They can be thought of as the perceived accessibility to a station based on simply observing the station and origin on a map. The study area excludes LSOAs located more than $15 \mathrm{~km}$ away from a Metrolink station. The phase of the station helps categorise length of exposure; areas with access to Phase $1 \& 2$ have had long-term exposure, while Phase 3 LSOAs have had short-term exposure.

As a sensitivity analysis, we also calculate a continuous measure of exposure: distance from each LSOA to its closest station. This allows us to test whether the effect of the new public transport is limited to a specific distance buffer and whether closer proximity corresponds with a higher likelihood

of gentrification. We expect gentrification effects to have a smaller effect as distance increases, and therefore apply a log transformation. We take the negative value of this transformed distance, so that a shorter distance (greater proximity) reflects greater exposure.

\subsection{Gentrification variables}

We define a series of gentrification change variables related to displacement and neighbourhood upgrading. For each gentrification variable, we calculate the percent change between 2011 and 2017 using Equation 1. We used the proportional change rather than the absolute difference because it reflects the change relative to baseline conditions.

$$
\Delta \mathrm{G} i j=\left(\mathrm{G} i j_{2017}-\mathrm{G}_{i j}{ }_{2011}\right) / \mathrm{Gij}{ }_{2011}
$$

Where:

$\Delta \mathrm{G} i j$ is the gentrification change variable, $i$, for LSOA $j$.

Gij, ${ }_{2011}$ and $\mathrm{G} i j{ }_{2017}$ are the 2011 and 2017 conditions for the same variable, $i$, for LSOA $j$. 

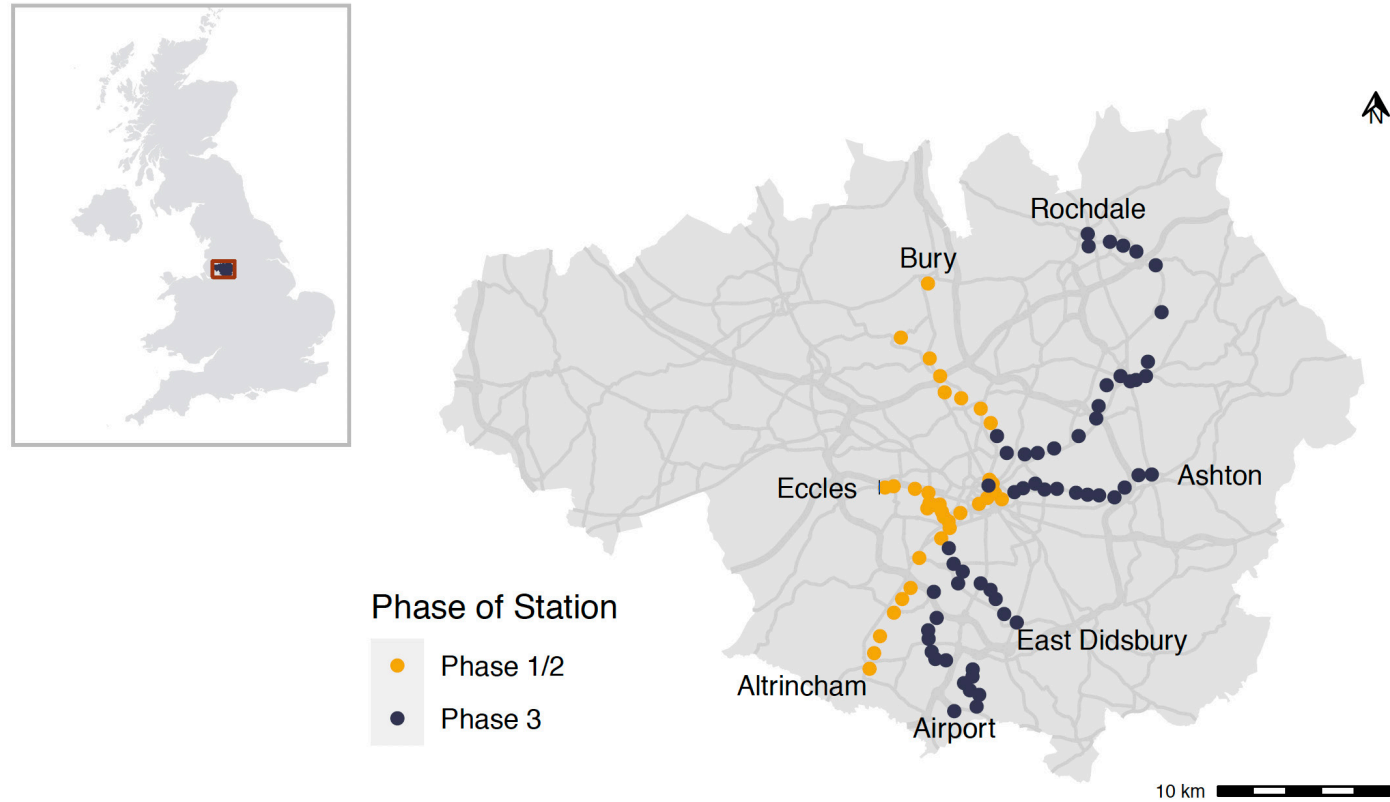

Figure 1. Metrolink stations within Greater Manchester by line and phase (data from: Ordnance Survey, 2019; Transport for Greater Manchester, 2019)

Displacement

Displacement reflects the negative consequences of gentrification and indicates whether more affluent in-movers are replacing original residents. This study includes the percent change in the proportion of elderly residents, median income, median house prices, and the number of annual property transactions as its displacement variables.

Monthly rent, professional employment, education levels, income, property prices, and owner-occupied dwellings are some of the measures most used to describe changes in resident make-up in previous studies (Bradway Laska et al., 1982; Dong, 2017; Grube-Cavers and Patterson, 2015; Kahn, 2007; Los Angeles Innovation Team, 2016; Mckinnish et al., 2009; Pollack et al., 2010; Zuk and Chapple, 2015). We assume median house price is a proxy for rental prices. The number of property transactions partially reflect the turnover of residents, with the caveat that high rental turnover is not necessarily reflected in the number of property sales. We expected the uplift in property value to increase property transactions, making the area less affordable and contributing to displacement. Property related variables indicate the cost of living in the neighbourhood, while income describes the socioeconomic status of its residents. We also look at age, as incumbent residents tend to be older than the gentrifiers (Hamnett, 1991; Marcuse, 1985; Zuk et al., 2018). Data for other measures such as education levels, household characteristics, employment levels, and migration were not available for the years of interest.

\section{Neighbourhood Upgrading Variables}

Neighbourhood upgrading is more complex. Past work has used sustainable travel mode share, population and employment density, existence of renovation, road safety, air pollution and ratings of community satisfaction which all relate to positive neighbourhood effects (Pollack et al., 2010; Social Exclusion Unit, 2003; Vigdor, 2002; Zuk and Chapple, 2015). Baker and Lee (2019) define most up- 
grading variables as products of TOD, such as population density, employment density, urban realm, and public transport use.

We use population density in this study as a measure of increased housing development and densification around public transport hubs. No areas were dense enough to be considered overcrowded, therefore it was not necessary to examine threshold effects of density where it could be considered a negative change. In addition to population density, we include a road safety variable. Child pedestrian casualties are listed by the Social Exclusion Unit (2003) as an indicator of accessibility. This study uses pedestrian and cyclist casualties of all severities and ages (to maximise dataset size). A reduction in casualties involving vulnerable road users would indicate improvements to the neighbourhood through urban realm or traffic improvements.

We considered data on employment density, public transport use or commuting mode, and urban realm improvements but these datasets are not publicly available for 2011 and 2017. While factors like street trees and pedestrian severance have been used in cross-sectional urban realm studies in London (Millard, Nellthorp, and Ojeda Cabral, 2018), such variables do not exist as a panel dataset for Manchester. We also considered using data on school ratings and crime, but these datasets do not provide adequate granularity.

\subsection{Propensity to gentrify}

Some gentrification studies analyse changes in all neighbourhoods (Atkinson, 2000; Dong, 2017; Kahn, 2007) of a study area, while others limit analysis to gentrifiable areas based on baseline conditions (Grube-Cavers and Patterson, 2015), or account for them as variables in their models (Baker and Lee, 2019). We adapt the approach of Vigdor (2002), Mckinnish, Walsh, and White (2009), and Baker and Lee (2019) and identify baseline gentrifiable characteristics prior to analysis but include all areas regardless of their propensity to gentrify (PTG).

We calculate a PTG score based on the performance of eight variables in 2011, prior to the study period. A high PTG score indicates greater propensity to be gentrified. The variables included are: the proportions of residents who are non-white, the proportions of residents who have higher education, the proportions of residents who are employed, the proportions of residents who are in professional occupations, the proportions of households in privately rented and owner occupied dwellings, the proportions of households with no car access, and housing prices (Table 1).

We account for ethnic minorities in this study due to the well-documented correlation between racial segregation in communities and deprivation (Atkinson, 2000; Pollack et al., 2010; Zuk and Chapple, 2015). Housing tenure reflects wealth in the area and indicates the likelihood of rent increases and development potential. Lower numbers of owner-occupied homes and high proportions of private rentals indicate the highest potential for land value uplift and displacement of original residents. While previous studies include car availability and employment rates as indicators of gentrification (Pollack et al., 2010), we include them in baseline PTG calculations instead because they rely on census data.

We expect LSOAs to be more susceptible to gentrification if performing relatively worse than the rest of the metropolitan area. How scholars define "worse" varies. Grube-Cavers and Patterson (2015) require all gentrifiable characteristics to be below the metropolitan average, while Zuk and Chapple (2015) looks for three out of four indicators to meet the threshold. Baker and Lee (2019) use a combined indicator based on the bottom quintile. Our study opts for three PTG groups rather than the binary classification of many previous studies to retain some of the complexity and observe any differential impacts in neighbourhoods with mixed characteristics.

For each of the eight PTG variables, we divide LSOAs into halves and categorise each as gentrifiable (a value of 1 ), or not (a value of 0$)^{3}$. More gentrifiable LSOAs have a proportion of non-white popula-

\footnotetext{
${ }^{3}$ We explored this by quartiles first.
} 
tion, proportion of households with no car access, and proportion of privately rented dwellings in the top half of the distribution (greater than the GM median). For the remaining five variables, LSOAs with in the bottom half of the distribution (less than the GM median) are more gentrifiable. PTG is the sum of all these variables, resulting in a score from zero to eight. This score is transformed into the three groups: low PTG (score of 0 to 2), medium PTG (score of 3 to 5 ) and high PTG (score of 6 to 8).

\subsection{Neighbourhood change}

We combine the change in individual gentrification variables (Section 3.5) to define Displacement and Neighbourhood Upgrading Indices, which then determine Neighbourhood Change Typologies, one of which is gentrification. The classification is at an LSOA level allowing us to identify specific neighbourhoods where these changes are occurring.

Table 1. Description and sources of variables

\begin{tabular}{|c|c|c|}
\hline Data & Description & Source \\
\hline \multicolumn{3}{|l|}{ Census Geographies } \\
\hline LSOA & $\begin{array}{l}\text { Population weighted centroids, bound- } \\
\text { aries }\end{array}$ & Office for National Statistics (2019e) \\
\hline MSOA & Boundaries & Office for National Statistics (2019e) \\
\hline \multicolumn{3}{|l|}{ Exposure } \\
\hline Metrolink Stations & $\begin{array}{l}\text { Station location, year opened, phase, } \\
\text { line (spatial dataset) }\end{array}$ & Transport for Greater Manchester (2019) \\
\hline \multicolumn{3}{|l|}{ PTG } \\
\hline Education & $\begin{array}{l}\text { Population with level } 4 \text { qualifications or } \\
\text { higher }\end{array}$ & Office for National Statistics (2019a) \\
\hline Employment & Population employed (full or part-time) & Office for National Statistics (2019a) \\
\hline Occupation type & Population in professional occupations & Office for National Statistics (2019a) \\
\hline Ethnicity & Population identifying as non-white & Office for National Statistics (2019a) \\
\hline Tenure - Owner Occupied & Owner occupied households & Office for National Statistics (2019a) \\
\hline Tenure - Privately Rented & Privately rented households & Office for National Statistics (2019a) \\
\hline Car Availability & Households with no car available & Office for National Statistics (2019a) \\
\hline Median House Price & $\begin{array}{l}\text { Median house price based on annual } \\
\text { transactions }\end{array}$ & Office for National Statistics (2019b) \\
\hline \multicolumn{3}{|l|}{ Gentrification - Displacement } \\
\hline Elderly Population & $\begin{array}{l}\text { Proportion of population over } 65 \text { years } \\
\text { of age }\end{array}$ & Office for National Statistics (2019a,d) \\
\hline Median Household Income & $\begin{array}{l}\text { Gross income estimates at the MSOA } \\
\text { level }\end{array}$ & Office for National Statistics (2019f) \\
\hline Median House Price & $\begin{array}{l}\text { Median house price based on annual } \\
\text { transactions }\end{array}$ & Office for National Statistics (2019b) \\
\hline $\begin{array}{l}\text { Number of Property Transac- } \\
\text { tions }\end{array}$ & $\begin{array}{l}\text { Number of annual property transac- } \\
\text { tions }\end{array}$ & Office for National Statistics (2019c) \\
\hline \multicolumn{3}{|c|}{ Gentrification - Neighbourhood Upgrading } \\
\hline Population Density & Population of LSOA & Office for National Statistics (2019d) \\
\hline Pedestrian and Cyclist Casualties & $\begin{array}{l}\text { Number of casualties involvinf pedes- } \\
\text { trian or cyclist }\end{array}$ & Department for Transport (2019) \\
\hline
\end{tabular}




\begin{tabular}{lll}
\hline Data & Description & Source \\
\hline $\begin{array}{l}\text { Confounding Variables } \\
\text { City Centre Ward }\end{array}$ & $\begin{array}{l}\text { Centroid of City Centre ward represents } \\
\text { CBD }\end{array}$ & Office for National Statistics (2019e) \\
Presence of Historic Buildings & $\begin{array}{l}\text { Listed buildings by grade (spatial data- } \\
\text { set) }\end{array}$
\end{tabular}

While we explored factor analysis and principal component analysis to construct the typologies, correlation tests between the constituent variables of each index show that they are poor candidates for either method. Therefore, these indices are determined using a discrete approach by comparing the change of a gentrification variable in a given LSOA relative to the rates of change in the rest of the region. In existing literature, the operationalisation of this comparison varies. Similar to Grube-Cavers and Patterson (2015) and the neighbourhood indices developed for the city of Los Angeles (Los Angeles Innovation Team, 2016), our method considers changes in a given variable that are above or below the median (depending on the variable) to characterise gentrification-like changes.

\section{Displacement Index}

The displacement index, $d \_$index, is based on the elderly population, income, median house price, and turnover. For the elderly population variable, if growth in an LSOA is in the bottom half (lower than the GM median), we assign the LSOA a value of 1 , indicating evidence of displacement. For the remaining three variables, based on income, median house price, and turnover, a rate of change higher than the GM median, corresponds with a value of 1, consistent with displacement trends (Marcuse, 1985). We sum the four values to arrive at a $d_{\text {_ }}$ score. Some LSOAs are missing data for one or more variables, therefore their maximum attainable $d$ _score may be less than four. We also take into account the $d$ _maximum value, the number of variables for which an LSOA has data. To convert the $d$ scores to a Displacement Index, while recognizing the heterogeneity of data available for each LSOA, we use d_score thresholds to assign each LSOA to one of three Displacement Index levels. Each threshold differs based on the d_maximum for the LSOA as outlined in Table 2.

Table 2. Displacement Index classification criteria

\begin{tabular}{llll}
\hline $\begin{array}{l}\text { Displacement Index }(\mathbf{d} \text { in- } \\
\text { dex })\end{array}$ & If d_maximum = 1 or $\mathbf{2}$ & If d_maximum $=\mathbf{3}$ & If d_maximum $=\mathbf{4}$ \\
\hline High Evidence & d_score $=2$ & d_score $=2$ or 3 & d_score $=3$ or 4 \\
Some Evidence & d_score $=1$ & d_score $=1$ or 2 & d_score $=1$ \\
No Evidence & d_score $=0$ & d_score $=0$ & d_score $=0$
\end{tabular}

Note: To work within the constraints of data available (d_maximum), we set different thresholds when classifying LSOAs as showing evidence of displacement, so that the maximum number of variables are taken into account.

\section{Neighbourhood Upgrading Index}

The Neighbourhood Upgrading Index, $n \_$index, relies only on population density data to determine the level of upgrading, as the road safety suffers from a small sample size and volatility in values and could not be used for this LSOA level analysis. Similar to the construction of the Displacement Index, we evaluate LSOA performance relative to the GM median. If population change is greater than the GM median, the LSOA is classified as having a Neighbourhood Upgrading Index of "some evidence." 
Compared to the Displacement Index, Neighbourhood upgrading is more conservative, with two levels indicating "no evidence" and "some evidence" of upgrading, reflecting the leaner contributing dataset.

Neighbourhood Change Typologies

We synthesise the displacement and neighbourhood indices and categorise LSOAs into four Neighbourhood Change Typologies: incumbent upgrading, gentrification, no change, and decline using the classification criteria in Table 3. Consistent with the operational definition of this study, evidence of both displacement and neighbourhood upgrading is necessary for gentrification. Upgrading without displacement leads to the ideal case for public transport investment, incumbent upgrading, while displacement without upgrading indicates neighbourhood decline.

Table 3. Neighbourhood Typology classification criteria

\begin{tabular}{lll}
\hline Neighbourhood Typology & Displacement Index (d_index $)$ & Neighbourhood Upgrading $\left(\mathbf{n} \_ \text {index }\right)^{*}$ \\
\hline Incumbent Upgrading & No Evidence & Some Evidence \\
Gentrification & Some or High Evidence & Some Evidence \\
No Change & No Evidence & No Evidence \\
Decline & Some or High Evidence & No Evidence
\end{tabular}

*Note: $n \_$index is only classified as "No Evidence" or "Some Evidence"

\subsection{Analyses}

We use multiple methods of analysis with the same variables and triangulate their results to better capture the true impact of LRT access on gentrification. As seen in the literature review, the methods used have a significant impact on the results and conclusions of studies. All analysis was performed using R Statistical Software (R Core Team, 2019).

Analysis 1: Exposure to LRT and gentrification.

We use a Difference in Difference (DiD) approach to test whether PTG and exposure, as well as the length of exposure, influences gentrification. $\mathrm{DiD}$ is a quasi-experimental approach that estimates the impact of an intervention. It compares the change in an outcome of the control group to that of the treated group and attributes a difference in these changes to the intervention, in this case exposure to a tram station.

We conduct two DiD analyses. For the first, LSOAs are divided into groups based on the three PTG groups and whether they are exposed to Metrolink stations (treated) or not (control). See Figure 1 (left) for a map of LSOAs. For each of our gentrification measures, the difference in the mean change between 2011 and 2017 is compared between exposed and non-exposed LSOAs of the same PTG group. For example, we compute the difference in means of a given measure between exposed and non-exposed LSOAs in the high PTG group.

The second $\mathrm{DiD}$ analysis further divides each treatment group by the length of exposure, or the phase of the station that it is exposed to. See Figure 2 (right) for a map of exposure and phase. While the non-exposed LSOAs can be considered as one control group, these are also divided based on the phase of the closest station providing an additional layer of spatial control to account for geographic differences in neighbourhoods that are not explicitly included. For example, we compute the difference in means between exposed and non-exposed LSOAs in the high PTG group close to Phase $1 \& 2$ stations separately to those close to Phase 3 stations. 
As a sensitivity analysis, we conduct linear regressions using the continuous exposure measure. For each gentrification variable, a series of models are computed to explain the change as a function of exposure and confounding variables (proximity to the city centre, and presence of historic buildings). The models are repeated for each PTG group. In this paper we only comment briefly on the results of the coefficient of the continuous exposure variable in relation to the $\mathrm{DiD}$ results as a sensitivity test.

Analysis 2: Indices and Neighbourhood Change Typologies

While Analysis 1 helps identify the relationship between individual gentrification variables, exposure, and PTG across the whole study area, neither determines gentrification as a composite phenomenon directly. Analysis 2 tests the relationship between the Displacement and Neighbourhood Upgrading Indices and Neighbourhood Change Typologies as they relate to PTG group and exposure to light rail. For this we conduct Pearson's Chi-squared tests to determine whether the classifications are independent or associated with exposure and PTG.

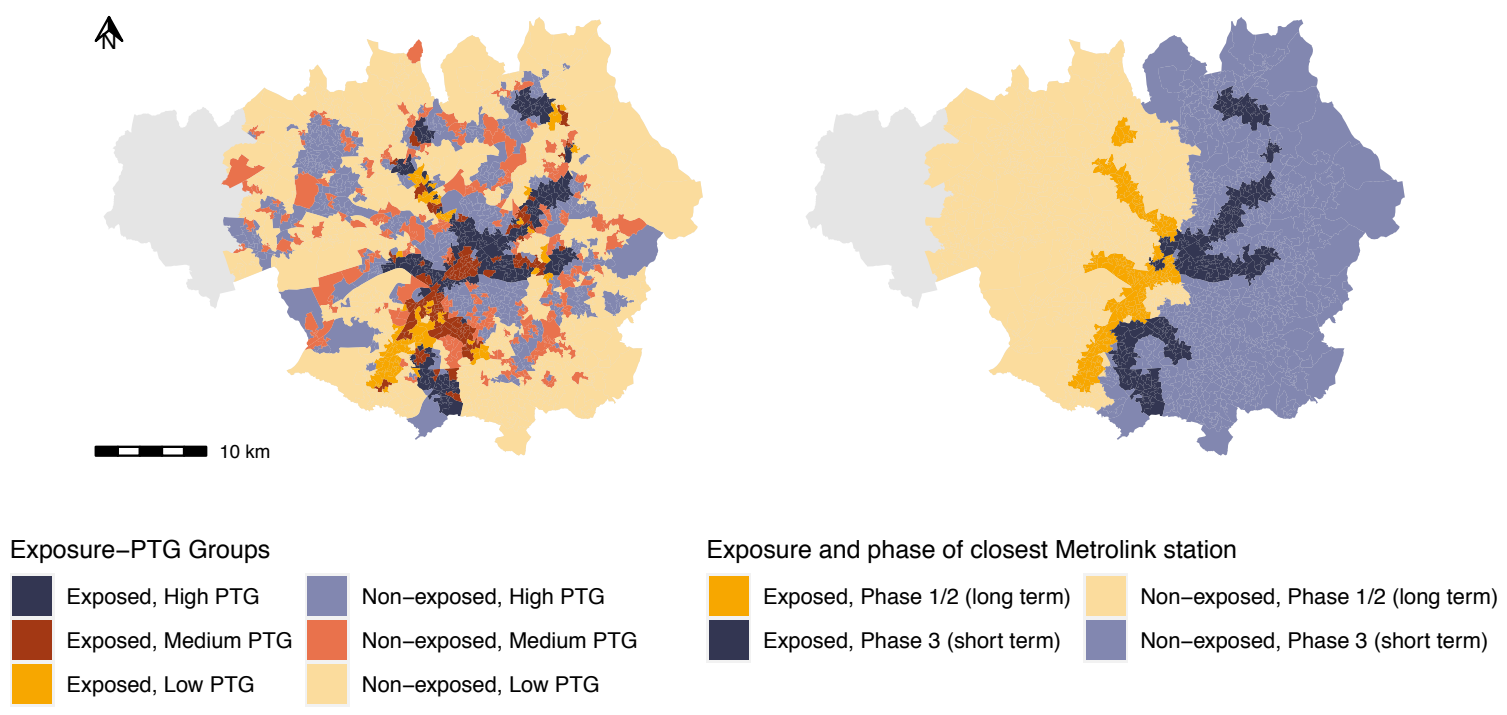

Figure 2. LSOAs in study area categorised by PTG group and exposure (left) and by phase of station and exposure (right). Study area excludes LSOAs in Greater Manchester located more than $15 \mathrm{~km}$ away from a Metrolink station. See Table 1 for all sources used.

\section{$4 \quad$ Results}

\subsection{Analysis 1: Gentrification impacts of exposure to light rail over time}

Table 4 shows the response of gentrification variables to exposure to a tram station, by PTG group. The results presented are the difference in means. If the difference in means is negative, the change in the exposed LSOAs is lower than the change in the unexposed control case, and vice versa. These effects are also disaggregated by exposure length, where short term exposure considers areas exposed to Phase 3 of the light rail network, and long-term exposure considers LSOAs exposed since Phase $1 \& 2$ of Metrolink.

Overall, we find mixed evidence of displacement and neighbourhood upgrading, and therefore gentrification as a result of exposure. The changes in elderly residents, property prices and turnover all suggest that there is evidence of displacement as a result of exposure to Metrolink stations, though 
income provides contrary results. Evidence of neighbourhood upgrading in response to public transport exposure are mixed; changes in population density support this, while pedestrian and cyclist safety results are inconclusive.

The length of exposure has a significant impact. Longer exposure typically results in a higher magnitude of change, and even flips the direction of influence in the case of some indicators. Exposure impacts displacement and neighbourhood upgrading differently depending on length of exposure.

While there are clearly differential impacts of exposure between the PTG groups, we cannot conclude that disinvested areas are more susceptible to gentrification. For example, high PTG areas are more susceptible to property value increases as a result of exposure, but low PTG areas show more evidence of population density changes. Low PTG groups tend to experience the more positive upgrading effects, while the impact on more vulnerable communities is mixed.

We now discuss the detailed findings by displacement and neighbourhood upgrading.

\section{Evidence of Displacement}

Table 4 shows a negative change in the proportion of elderly residents in exposed areas compared to areas without tram station access. This relative change is more present in low PTG (more affluent) neighbourhoods than high PTG neighbourhoods. Nevertheless, all exposed areas show similar patterns. Long term exposure in medium and low PTG LSOAs has stronger (and significant) impacts, but in high PTG neighbourhoods short term exposure has a stronger impact. This could be explained by how the Metrolink network has developed. A larger proportion of low PTG areas have had long term exposure compared to the high PTG neighbourhoods, which were largely served by Phase 3 . The relative statistical significance reflects the unequal sample sizes - the larger sample of low PTG groups with longerterm impact means that this group presents more statistically significant results than high PTG groups. This pattern is present in several gentrification variables.

Property prices have grown at a faster rate in areas exposed to Metrolink than non-exposed LSOAs. We observe high and significant changes in low PTG areas. The impact on medium and high PTG areas is also positive though smaller and not significant. Differentiating the results by length of exposure reveals that long term exposure to public transport is largely responsible for the property value uplift in low PTG areas, while changes associated with short term exposure are not significant. High PTG (disinvested) areas with long term exposure demonstrate very high and significant growth in property values.

If we only consider overall property turnover, it appears to be negatively affected by exposure to Metrolink. However, if we disaggregate results by exposure length, this indicator highlights the nuances in impact; newly exposed areas have depressed (negative) turnover rates, while longer-term exposure results in higher (positive) rates of sales. Previous studies of neighbourhoods undergoing change have found evidence of initially depressed turnover rates as well (Chapple et al., 2017b; Zuk et al., 2018). They reflect residents' resistance to displacement in the initial stages of gentrification even as rents increase. Property owners also prolong ownership to benefit from the property uplift. These patterns are predominantly seen in low and medium PTG areas. Turnover in high PTG areas show evidence of similar directions of influence but the differences are not significant. The lack of significant relationships between turnover and exposure of high PTG LSOAs may also reflect the ownership structures in these neighbourhoods. Many of the most deprived communities have high concentrations of social housing units; property sales data do not highlight changes in these areas.

In contrast to the evidence of displacement in the previous three variables, income effects for low and high PTG areas are both negative which suggests that higher-income gentrifiers are not replacing lower-income residents, and that the average income is in fact decreasing. We observe similar trends 
independent of length of exposure. While these socioeconomic changes may reflect reality, we also postulate that the range of findings may be due to geographic data granularity issues. The dependent gentrification variable is based on the larger MSOA areas, while exposure (the independent variable) reflects LSOA level changes. The discrete cut-off between exposed and non-exposed LSOAs can divide an MSOA, assigning the same income values to exposed and non-exposed LSOAs.

The sensitivity tests, using a continuous measure of exposure, yield similar results for the four variables with only slight variations in significance and magnitude. For example, the coefficient of exposure is negative and significant for all PTG groups for the elderly population variable, while the DiD results are also all negative, though only significant for the low PTG group. For median house prices, both the sensitivity test and the DiD results are positive for all PTG groups, and significant for only low PTG areas.

\section{Evidence of Neighbourhood Upgrading}

The results for population density shown in Table 4, overall, do not suggest an association with exposure to Metrolink stations. In contrast, if we consider LSOAs with long- and short-term exposure

separately, we observe higher rates of population growth in areas with long term exposure, supporting the hypothesis that these areas experienced higher rates of development. The opposite is true with more recent access to stations, especially for low PTG areas-population density changes are negative. This trend could be expected if development has not followed the construction of a tram station. Without a substantial increase in new housing units, levels of occupancy in existing units may decrease due to younger professionals without children replacing larger families.

Pedestrian and cyclist casualties show varied evidence of upgrading in response to exposure to tram stations. Table 4 shows casualties are significantly higher in high PTG areas with exposure to tram stations, and lower in more affluent, low PTG areas. High PTG LSOAs are more significantly impacted by short term exposure, while for low PTG areas, long term exposure is more pronounced. This difference may be due to sample size, as mentioned previously. In addition, LSOAs towards the core tend to be higher PTG, and likely experience denser traffic. Introducing a new station may exacerbate vehiclepedestrian interactions as more people access the area. Changes in the active travel share in central areas, may also result in more vulnerable travelers which the casualties are not adjusted for.

The sensitivity tests, using a continuous measure of exposure, yield fairly similar results although the significance and magnitude varies. For example $\mathrm{DiD}$ analysis results for pedestrian and cyclist casualties are significant for high PTG areas, while the sensitivity test is significant for both low and high PTG areas; the direction of influence for each PTG group is the same for both analyses. 


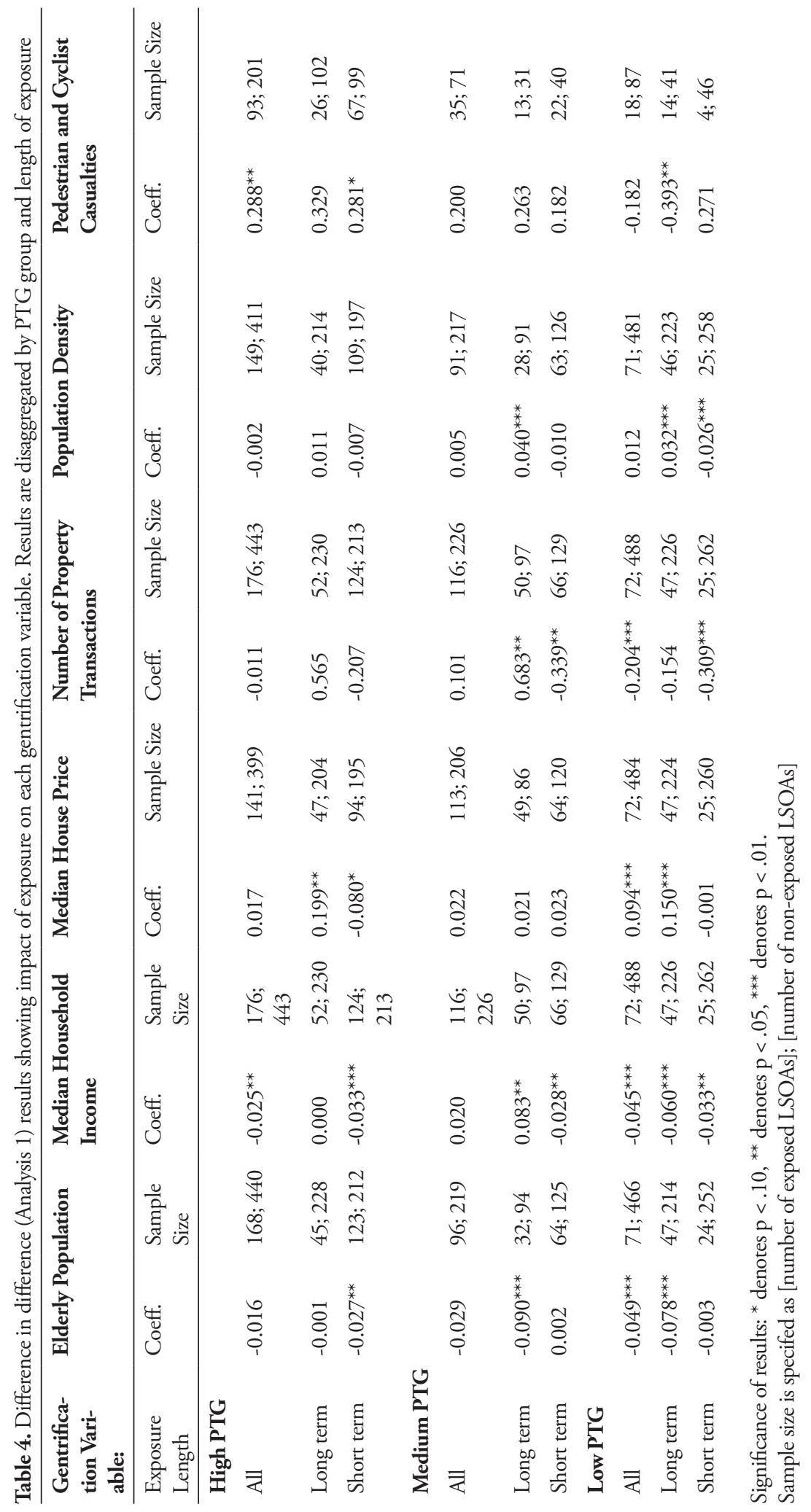




\subsection{Analysis 2: Neighbourhood change in response to light rail exposure}

The following sections describe how exposure and PTG relate to the Displacement and Neighbourhood Upgrading Indices and the resulting Neighbourhood Typologies. Analysis 2 suggests a positive correlation between exposure and both neighbourhood upgrading and gentrification, independent of PTG group. We do not find statistically significant evidence of exposure impacting one PTG group more than another. Independent of exposure, we consistently see strong relationships between higher PTG areas and displacement, neighbourhood upgrading, and gentrification. We confirm that observations between the indices/typologies are significantly associated with exposure and PTG using Chisquare tests.

Figure 3 and the associated Chi-square test results show that exposure and displacement are not closely associated with each other, both within each PTG group, and when considering all LSOAs together. In the highest PTG LSOAs, a higher proportion of exposed LSOAs show "high evidence" of displacement than compared to non-exposed areas, however a higher proportion of exposed LSOAs are also observed to have "no evidence" of displacement. This relationship is also apparent when considering all PTG groups together. While some patterns can be observed, the associations are not statistically significant.

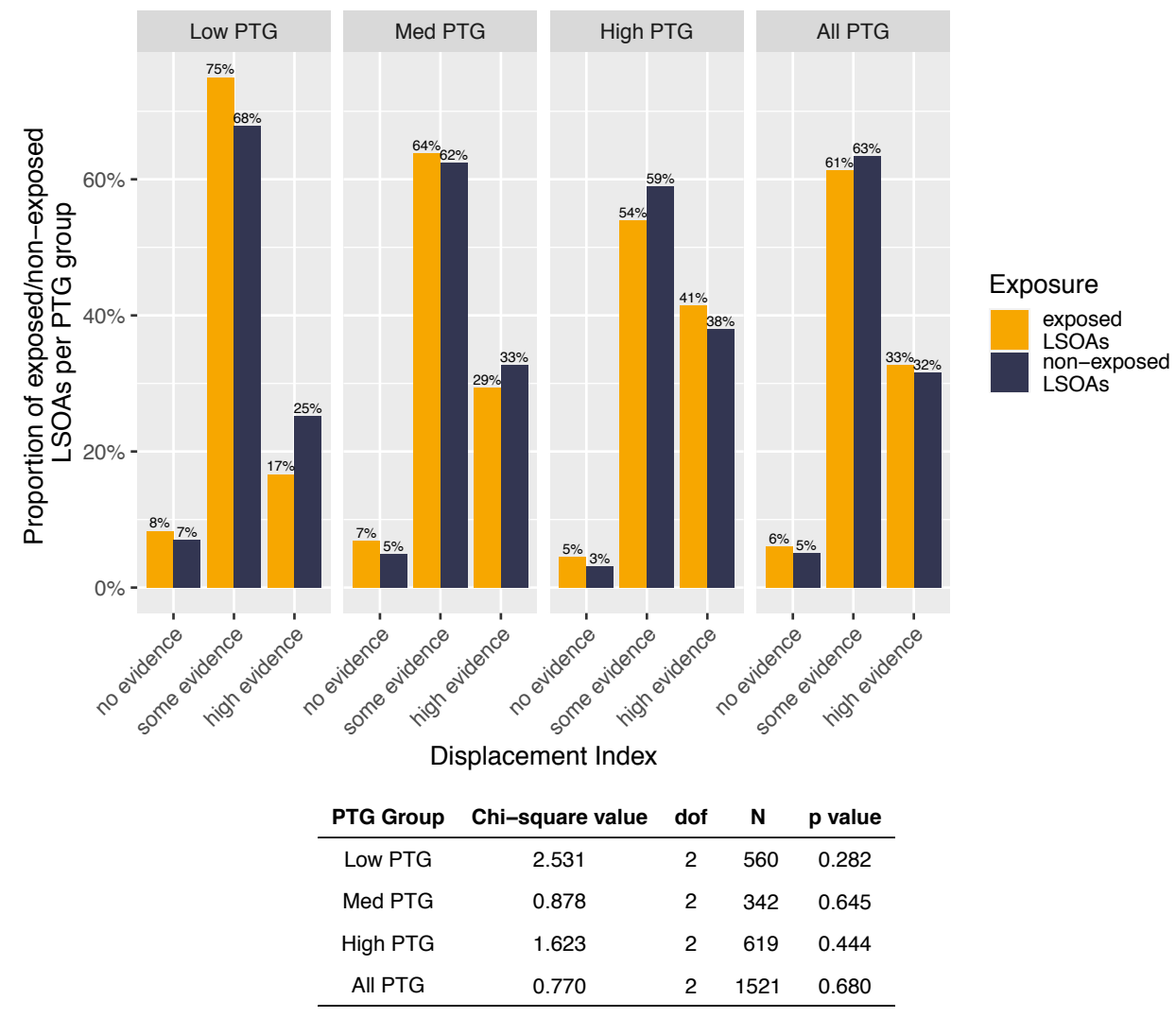

Figure 3. Proportion of exposed/non-exposed LSOAs vs. Displacement Index, by PTG group. Exposure is not significantly associated with the Displacement Index ( $\mathrm{p}>0.05)$. 
Figure 4 displays the results for the Neighbourhood Upgrading Index. The Chi-square tests show that when considering all LSOAs, exposure is significantly associated with "some evidence" of upgrading. ( $\mathrm{p}$ 0.005). A significant relationship does not exist between exposure and neighbourhood upgrading within PTG groups.

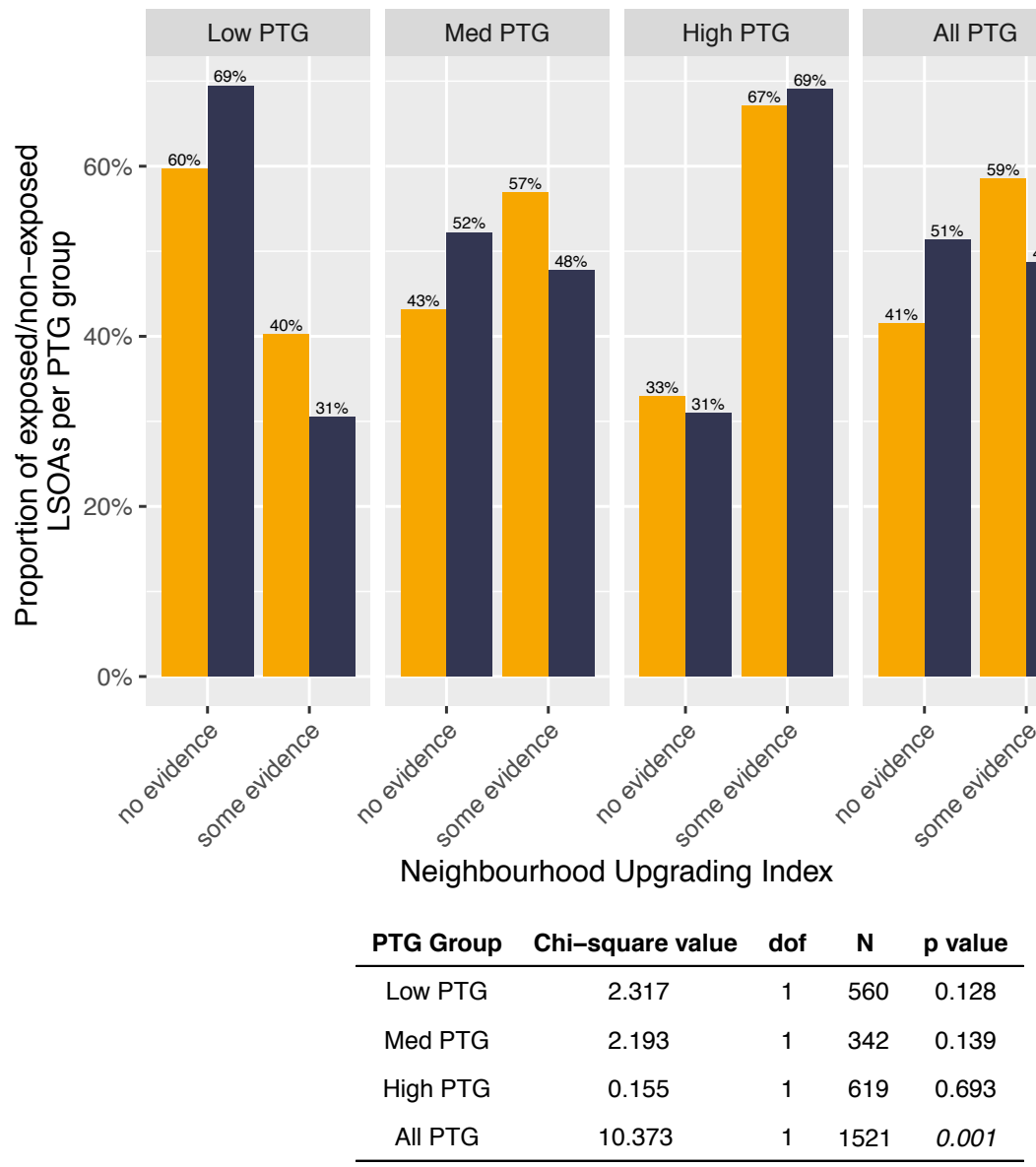

Figure 4. Proportion of exposed/non-exposed LSOAs vs. Neighbourhood Upgrading Index, by PTG group. Exposure is significantly associated with neighbourhood upgrading when considering all PTG groups $(\mathrm{p}<.005)$.

Figure 5 illustrates a similar pattern to Figure 4. The Chi-square tests show that exposure is significantly associated with the typologies with higher levels of gentrification and lower levels of decline $(\mathrm{p}<0.01)$. There is no significant relationship between exposure and the neighbourhood change typologies within PTG groups. Gentrification is the most prevalent neighbourhood change in areas exposed to LRT. 


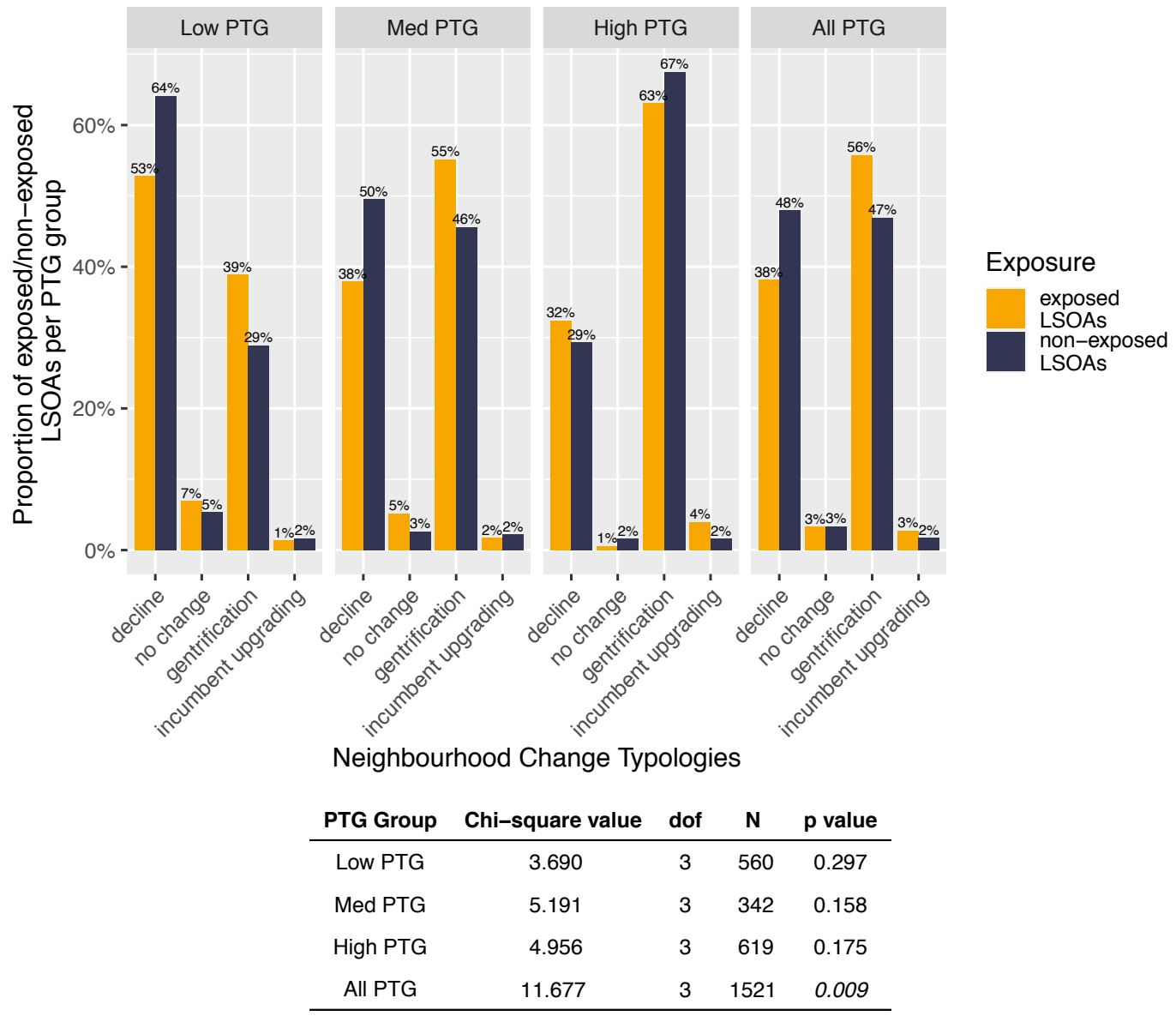

Figure 5. Proportion of exposed/non-exposed LSOAs vs. Neighbourhood Change Typologies, by PTG group. Exposure is significantly associated with the Neighbourhood Change Typologies when considering all PTG groups $(\mathrm{p}<.01)$.

From the three preceding analyses, we conclude that exposure is significantly related to neighbourhood upgrading and gentrification. While the direction of influence is the same, exposure is not significantly related to displacement. Moreover, exposure does not have a differential impact on PTG group. For example, higher PTG, or more deprived areas, are not more or less susceptible to gentrification-related changes due to exposure than lower PTG, or more affluent, areas. However, Figure 6 and associated Chi-square tests do show a very strong relationship between PTG and gentrification-related changes. Higher PTG LSOAs are more susceptible to displacement, neighbourhood upgrading and gentrification than their lower PTG counterparts, independent of exposure. The findings confirm the necessity of evaluating distributional impacts between communities of relative affluence and deprivation. While Analysis 2 does not find conclusively that exposure to LRT impacts these types of communities differently, they do ultimately face greater levels for gentrification like change due to other factors. 


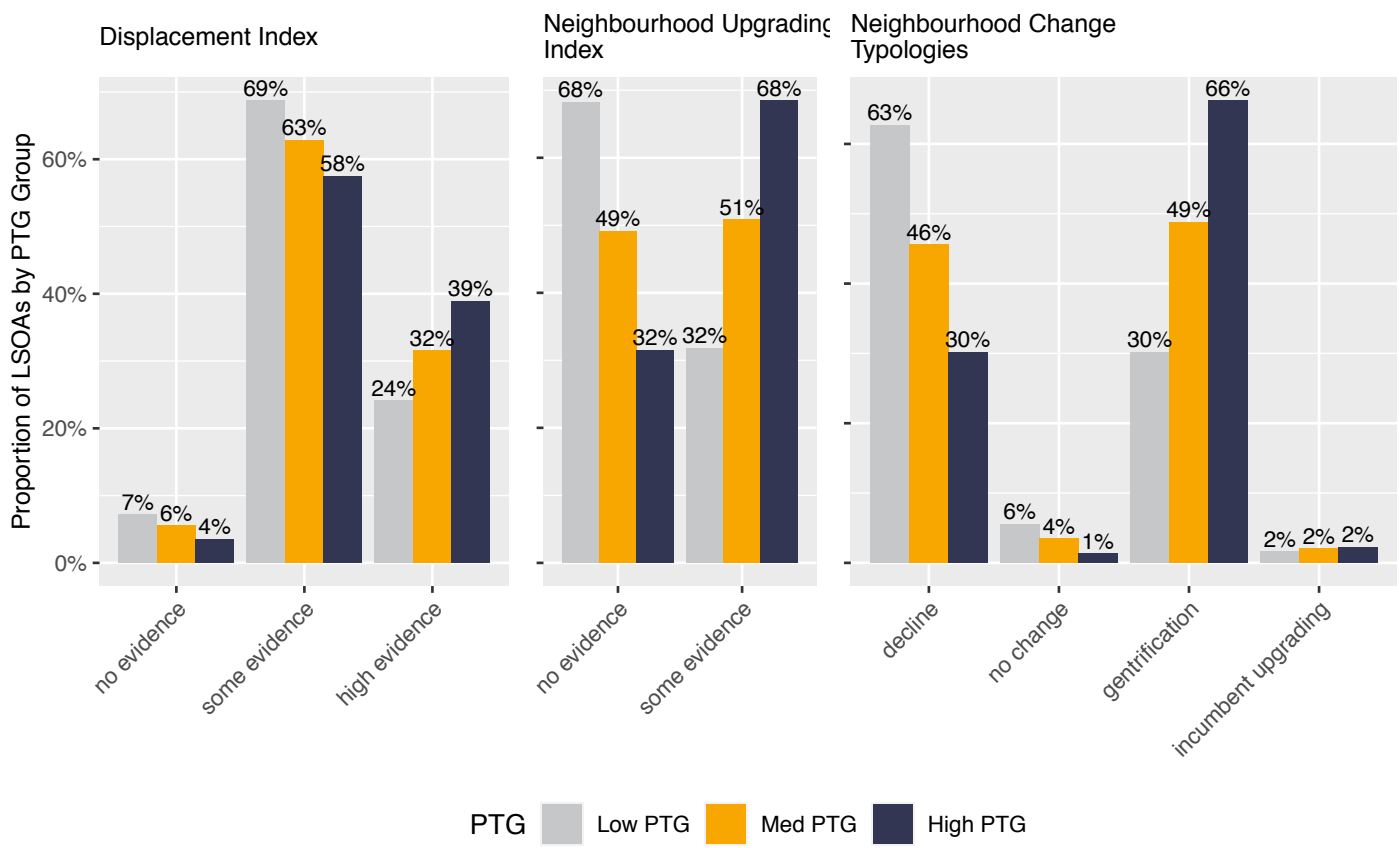

Figure 6. Proportion of LSOAs by PTG vs. Displacement Index, Neighbourhood Upgrading Index, and Neighbourhood Change Typologies, respectively. Chi-square tests confirm that all indices/typologies are very strongly associated with PTG groups $(\mathrm{p}<.001)$.

\section{Discussion}

This paper contributes to the gentrification literature by examining the link between new LRT investment and gentrification. As cities develop more sustainable travel options for their residents, understanding their wider and distributional impacts becomes increasingly relevant. This research is unique in its multi-analysis approach to studying gentrification on a bi-axial framework of neighbourhood change: displacement and neighbourhood upgrading. We focus specifically on the extent to which exposure to public transport induces gentrification-like changes in neighbouring communities, how time plays a role in the types and magnitude of changes, and whether disinvested (high PTG) areas are most susceptible.

The outcomes of the two analyses together show that that gentrification and its constituent variables are amplified in areas with LRT access. Although DiD analyses can be interpreted as demonstrating causal relationships between exposure and gentrification variables, we hesitate to conclude with confidence that exposure to transport induced gentrification in GM. Nevertheless, the DiD results provide clear evidence that the magnitude and even direction of impact vary significantly with length of exposure. Although some indicators, such as income, produce counterintuitive results, we think this is due to data granularity issues. The results from the neighbourhood-level change analysis show that exposure is significantly related to neighbourhood upgrading and gentrification, while its relationship to displacement does not appear significant. Though exposure does not appear to affect PTG groups differentially, higher PTG, independent of exposure is strongly associated with displacement, upgrading and gentrification. Gentrification is also the most prevalent typology in areas exposed to public transport. The results provide quantitative confirmation of patterns of gentrification happening in disinvested areas of GM and areas exposed to LRT, though the combination of the two does not appear to have a significant relationship.

Our results support the literature which has found significant relationships between light rail access and gentrification, based on sociodemographic and property-related variables in at least some urban 
areas (Baker and Lee, 2019; Barton and Gibbons, 2017; Chapple et al., 2017b; Grube-Cavers and Patterson, 2015; Pollack et al., 2010). Though many of these studies found mixed results based on applying a single method to multiple geographies, our study finds slightly different results due to two different methods applied to the same geography. Application of our methods to more cities in the UK that are investing in light rail networks would provide a further addition to the body of literature which is dominated by studies from North America.

The findings on whether disinvested areas are more susceptible to gentrification-like changes due to LRT exposure are varied. When analysing individual variables of change, in some cases high-PTG areas show evidence of gentrification, for example, property value uplift, while in other cases, such as improvements in road safety, gentrification-like changes are more apparent in affluent areas. In Analysis 2, the Neighbourhood Change Typologies show negative trends over the study period in higher PTG (disinvested) areas than low PTG communities, independent of LRT exposure. However, the impact of exposure does not differ between PTG groups. One reason for this may be that a greater proportion of high PTG communities gained LRT exposure more recently which may explain the lack of more significant impacts for this group.

Due to differences in methods, we cannot perform a detailed comparison between our results and previous studies accounting for gentrifiable-ness (e.g., Baker and Lee, 2019). Our three-tier classification of gentrifiable areas using PTG is unique and allows observations of more gradual changes, which may not appear as obvious as the binary classifications adopted by previous studies. The three levels of PTG allow for a more nuanced investigation of gentrification, which we believe adds dimension to the predominantly binary classifications in the existing literature. Our findings show that segmenting neighbourhoods by vulnerability criteria is vital during impact analysis. Not doing so risks conclusions that equate gentrification-like changes in deprived areas with more affluent ones though the consequences of displacement pressure on the groups are not comparable.

One of the strongest patterns to emerge from the analysis is the importance of length of exposure. Each gentrification variable exhibits different behaviour depending on whether an area had long term exposure (i.e., Phase $1 \& 2$ construction of LRT), or was exposed more recently (i.e., Phase 3). In some cases, length of exposure impacts the magnitude and/or significance of a change, yet in other cases, length of exposure changes the direction of influence.

While areas with long term access to stations do not gain exposure during the study timeline (2011 to 2017), the impact of public transport exposure is stronger in these areas. There may be two explanations for this finding. Either these areas experienced gentrification closer to the initial time of exposure, and are continuing to experience similar changes, or they are only realising pronounced impacts more than a decade or two since opening. Regardless, our findings have implications on the timing of policies, interventions, and ex-post evaluations. Building on Baker and Lee (2019) who comment on differences in results for cities with twenty and thirty-year-old light rail networks, our results corroborate but are more consistent in showing higher magnitude of impact due to long term exposure. Chapple et al. (2017b) also acknowledge the importance of considering longer time frames to capture gentrification which does not necessarily happen at the speed with which it is portrayed in the media. Length of exposure is a crucial variable to include to fully and correctly capture the impact of transport investments.

Current appraisal methods of future projects are completed based on estimated benefits to existing residents, or incumbent upgrading (e.g., Department for Transport, 2018; 2019). We do not see adequate evidence of this theoretical scenario in our ex-post evaluation of Metrolink which raises questions about the validity of existing social impact appraisal methods. We also observe in the Displacement Index analysis that there are very few LSOAs which exhibit "no evidence" of displacement, rather most fall into the "some" or "high evidence" categories. Furthermore, neighbourhoods experiencing decline and gentrification far outnumber those without signs of change or undergoing incumbent upgrading. 
Despite the fact that this research provides a unique multi-analysis approach to studying gentrification using a bi-axial framework of neighbourhood change and investigates impacts over time and by level of community vulnerability, our research has some limitations. First, the limits of this study point to future work utilising a broader and more complete set of data, within its dual-axis framework. For example, neighbourhood upgrading can be described by several additional factors, such as employment density, land-use changes, and Metrolink patronage. While we use four variables to study displacement, there are additional valuable sociodemographic indicators that are limited to census data sources. Repeating a similar study after the 2021 Census would mean access to a rich panel dataset of three decades, starting from before Phase 1 of Metrolink was opened. Second, improvements in data granularity, such as fine-grained income data would also help isolate the effect of exposure on income without being obscured by the discrepancies in data geographies. Third, the study approach could be improved by adopting a PTG classification with more uniform population sizes. Differences in the number of LSOAs in each PTG group made for more challenging interpretations of some results.

Finally, triangulating our results by applying multiple methods builds on the works of current studies in the field that typically favour a single set of analyses. Synthesising the results of multiple analyses sometimes results in difficult-to-explain-findings, like the different conclusions with respect to the influence of PTG in each of our methods. This difficulty, however, highlights the merit of approaching research aims from several angles and manipulating the same data in diverse ways. The variation in results should alert the reader to be critical when approaching literature and future work on the subject. Results need to be interpreted in the context of the data used, the methods employed, and the operational definition of the study.

\section{Conclusion}

Understanding whether investments induce gentrification is essential to ensure investment in sustainable transport is not undermined by the displacement it may create. Using a unique multi-analysis approach to studying gentrification and a bi-axial framework of neighbourhood change: displacement and neighbourhood upgrading, we show that gentrification is likely occurring in neighbourhoods that gain light rail access in Manchester, UK. Our work highlights the importance of considering long term impacts and differentiating between neighbourhoods particularly vulnerable to such changes. More deprived communities, we find, are strongly associated with gentrification-like changes. Transport improvements are not solely responsible for gentrification, rather, we demonstrate that they are a constituent player. Transport professionals have the opportunity to collaborate with housing policy makers and land-use planners to mitigate the consequences of gentrification, while public transport services are improved in both an environmentally and socially sustainable manner. The findings of this study are of relevance to future researchers, planners, and policy makers looking to ensure transport investments are serving the populations they are intended to serve. 


\section{References}

Atkinson, R. 2000. Measuring gentrification and displacement in Greater London. Urban Studies, 37(1):149-166.

Baker, D. M. and B. Lee. 2019. How does light rail transit (LRT) impact gentrification? Evidence from fourteen US urbanized areas. Journal of Planning Education and Research, 39(1):35-49. ISSN 0739456X. doi: 10.1177/0739456X17713619.

Barton, M. S. and J. Gibbons. 2017. A stop too far: How does public transportation concentration influence neighbourhood median household income? Urban Studies, 54(2):538-554.

Bradway Laska, S., J. M. Seaman, and D. R. McSeveney. 1982. Inner-City Reinvestment: Neighborhood Characteristics and Spatial Patterns Over Time. Urban Studies, 19(2):155-165. ISSN 00420980. doi: 10.1080/00420988220080281.

Cervero, R. 1984. Light rail transit and urban development. Journal of the American Planning Association, 50(2):133-147. ISSN 01944363. doi: 10.1080/01944368408977170.

Chapple, K., A. Loukaitou-Sideris, S. R. González, D. Kadin, and J. Poirier. 2017a. Transit-Oriented Development \& Commercial Gentrification: Exploring the Linkages. Technical report, UCB Center for Community Innovation \& UCLA Lewis Center. URL https://trid.trb.org/ view/1486274.

Chapple, K., P. Waddell, D. Chatman, M. Zuk, A. Loukaitou-Sideris, P. Ong, S. R. Gonzalez, C. Pech, and K. Gorska. 2017b. Developing a new methodology for analyzing potential displacement. Technical report, University of California, Berkeley; University of California, Los Angeles. URL https:// www.arb.ca.gov/research/apr/past/13-310.pdf.

Church, A., M. Frost, and K. Sullivan. 2000. Transport and social exclusion in London. Transport Policy, 7:195-205.

Clay, P. L. 1979. Neighborhood renewal: Middle-class resettlement and incumbent upgrading in American neighborhoods. Free Press.

Department for Transport. 2018. TAG unit A2-1 Wider economic impacts. Technical report. URL https://assets.publishing.service.gov.uk/government/uploads/system/uploads/attachment_data/ file/556077/webtag-wider-economic-impact-appraisal-tag-unit-a21. pdf.

Department for Transport. 2019. Road safety data: Accident, vehicle and casualty data (STATS19). URL http://data. gov.uk/.

Dobbs, L. 2005. Wedded to the car: Women, employment and the importance of private transport. Transport Policy, 12(3):266-278.

Dong, H. 2017. Rail-transit-induced gentrification and the affordability paradox of TOD. Journal of Transport Geography, 63:1-10. ISSN 09666923. doi:10.1016/j.jtrangeo.2017.07.001.

Ellen,I. G., K.Mertens Horn, and D. Reed. 2017. Has Falling Crime Invited Gentrification? doi:10.2139/ssrn.2930242.

Glass, R. 1964. London: Aspects of Change. London: MacGibbon \& Kee. ISBN 1618199. doi:10.1080/00420986420080381.

Grube-Cavers, A. and Z. Patterson. 2015. Urban rapid rail transit and gentrification in Canadian urban centres: A survival analysis approach. Urban Studies Journal Limited, 52(1):178-194. doi: 10.1177/0042098014524287. URL https://journals.sagepub.com/doi/pdf/10.1177/ 0042098014524287.

Hamnett, C. 1991. The blind men and the elephant: The explanation of gentrification. Royal Geographical Society, 16(2):173-189. doi: 10.2307/2786835.

Hess, D. B. and T. M. Almeida. 2007. Impact of proximity to light rail rapid transit on station-area property values in Buffalo, New York. Urban Studies, 44(5-6):1041-1068. ISSN 00420980. doi: 10.1080/00420980701256005. 
Historic England. 2019. National Heritage List for England: Listed buildings spatial data. URL https:// historicengland.org.uk.

Hyra, D. 2014. The back-to-the-city movement: Neighbourhood redevelopment and processes of political and cultural displacement. Urban Studies, 52(10):1753-1773. ISSN 1360063X. doi: 10.1177/0042098014539403.

Johnson, D., M. Ercolani, and P. Mackie. 2017. Econometric analysis of the link between public transport accessibility and employment. Transport Policy, 60(May):1-9. ISSN 1879310X. doi: 10.1016/j. tranpol.2017.08.001.

Kahn, M. E. 2007. Gentrification trends in new transit-oriented communities: Evidence from 14 cities that expanded and built rail transit systems. Real Estate Economics, 35(2):155-182.

Keddie, J. 2014. Negotiating urban change in gentrifying London: Experiences of long-term residents and early gentrifiers in Bermondsey. Ph.D. thesis, London School of Economics and Political Science.

Knaap, G. J., C. Ding, and L. D. Hopkins. 2001. Do plans matter? The effects of light rail plans on land values in station areas. Journal of Planning Education and Research, 21(1):32-39. doi: 10.1177/0739456X0102100103.

Knowles, R. D. and F. Ferbrache. 2016. Evaluation of wider economic impacts of light rail investment on cities. Journal of Transport Geography, 54:430-439. ISSN 09666923. doi: 10.1016/j. jtrangeo.2015.09.002.

Lees, L. 2000. A reappraisal of gentrification towards a geography of gentrification. Progress in Human Geography, 24:389-408.

Lees, L. 2003. Super-gentrification: The case of Brooklyn Heights, New York City. Urban Studies, 40(12):2487-2509. ISSN: 00420980. doi: 10.1080/0042098032000136174.

Lees, L., T. Slater, and E. Wyly. 2013. Gentrification. Taylor \& Francis. ISBN 9781135930240. URL https://books. google.co.uk/books?id=TQqPAQAAQBAJ.

Ley, D. 1986. Alternative explanations for inner-city gentrification: A Canadian Assessment, Annals of the Association of American Geographers, 76(4):521-535.

Los Angeles Innovation Team. 2016. LA Indices of Neighbourhood Change and Displacement Pressure. URL http://lahub.maps.arcgis.com/apps/MapJournal/index.html?appid=e3f1806c03fc4d0cb c7145aad8e 523d9.

Lucas, K. 2012. Transport and social exclusion: Where are we now? Transport Policy, 20:105-113. ISSN 0967070X. doi: 10.1016/j.tranpol.2012.01.013.

Lucas, K., I. Philips, C. Mulley, and L. Ma. 2018. Is transport poverty socially or environmentally driven? Comparing the travel behaviours of two low-income populations living in central and peripheral locations in the same city. Transportation Research Part A: Policy and Practice, 116:622-634. ISSN 0965-8564. doi: 10.1016/J.TRA.2018.07.007.

Lucas, K., S. Tyler, and G. Christodoulou. 2008. Who Benefits, How and Why? Technical report, University of Westminster, York.

Marcuse, P. 1985. Gentrification, abandonment, and displacement: Connections, causes, and policy responses in New York City. Washington University Journal of Urban and Contemporary Law, 28 (January):195-240. ISSN 02729490. doi: 10.1525/sp.2007.54.1.23. arXiv:1011. 1669v3.

Markovich, J. and K. Lucas. 2011. The social and distributional impacts of transport: A literature review. Working Paper $\mathrm{N}^{\circ} 1055$, University of Oxford Transport Studies Unit.

Mckinnish, T., R. Walsh, and K. White. 2009. Who gentrifies low-income neighbourhoods? Journal of Urban Economics, 67(2):180-193.

Medda, F. 2012. Land value capture finance for transport accessibility: A review. Journal of Transport Geography, 25:154-161. ISSN 09666923. doi:10.1016/j.jtrangeo.2012.07.013. 
Mejia-Dorantes, L. and K. Lucas. 2014. Public transport investment and local regeneration: A comparison of London's Jubilee Line Extension and the Madrid Metrosur. Transport Policy, 35:241-252. ISSN 0967070X. doi: 10.1016/j.tranpol.2014.05.020.

Melchert, D. and J. L. Naroff. 1987. Central city revitalization: A predictive model. Real Estate Economics, 15(1):664-683. URL https:/econpapers.repec.org/RePEc:bla:reesec:v:15:y:1987:i:1 :p:664-683.

Millard, T., J. Nellthorp, and M. Ojeda Cabral. 2018. What is the value of urban realm? - a crosssectional analysis in London. In International Transportation Economics Association Conference, June, pp. 25-29. Hong Kong. URL https://editorialexpress.com/cgi-bin/conference/ download. cgi?db_name=ITEA2018 $\{\&\}$ paper_id=176.

Office for National Statistics. 2019a. 2011 Census aggregate data. URL https://www.nomisweb.co.uk/.

Office for National Statistics. 2019b. House Prices for Small Statistical Areas: Median house prices by lower layer super output area: HPSSA dataset 46. URL https://www.ons. gov.uk/.

Office for National Statistics. 2019c. House Prices for Small Statistical Areas: Residential property sales by lower LSOA: HPSSA dataset 41. URL https://www.ons.gov. uk/.

Office for National Statistics. 2019d. Lower layer Super Output Area population estimates (National Statistics). URL https://www.ons.gov.uk/.

Office for National Statistics. 2019e. Office for National Statistics, 2011 Census: Digitised Boundary Data. URL http://geoportal.statistics.gov.uk/.

Office for National Statistics. 2019f. Small area income estimates for middle layer super output areas, England and Wales. URL https://www.ons.gov.uk/.

Ordnance Survey. 2019. OS Open Roads. URL https: //www.ordnancesurvey.co.uk/business-and-government/ products/os-open-roads.html.

Pollack, S., B. Bluestone, and C. Billingham. 2010. Maintaining Diversity In America's Transit-Rich Neighborhoods: Tools for Equitable Neighborhood Change. New England Community Developments, (1):1-68. URL http://www.northeastern.edu/dukakiscenter/ wp-content/uploads/2011/12/ TRN_Equity_final.pdf.

R Core Team (2019). R: A language and environment for statistical computing. R Foundation for Statistical Computing, Vienna, Austria. URL https:/www.R-project.org/.

Rérat, P. and L. Lees. 2018. Evidence from Swiss core cities spatial capital, gentrification and mobility. Transactions of the Institute of British Geographers, 36(1):126- 142.

Rodríguez, D. A. and F. Targa. 2004. Value of accessibility to Bogotás bus rapid transit system. Transport Reviews, 24(587-610). ISSN 1464-5327. doi: 10.1080/0144164042000195081.

Smith, N. 1987. Gentrification and the Rent Gap. Annals of the Association of American Geographers, 77(3):462- 465. ISSN 0004-5608. doi: 10.1111/j.1467-8306.1987.tb00171.x.

Social Exclusion Unit. 2003. Making the Connections: Final Report on Transport and Social Exclusion. Technical report.

Soursourian, M. 2010. Equipping Communities to Achieve Equitable Transit-Oriented Development. Community Investments, 22(2):22-28. URL https://core.ac.uk/ download/pdf/6238529.pdf.

Transport for Greater Manchester. 2019. Metrolink station spatial data.

Transport for London. 2017. Land value capture, Final report. Technical report. URL https://www. london.gov.uk/sites/default/files/land_value_capture_report_transport_for_london.pdf.

Turner, M. A. 2001. Leading indicators of gentrification in DC neighborhoods: DC Policy Forum, proceedings.

United Nations Department of Economic and Social Affairs Population Division. 2019. World Urbanization Prospects 2018: Highlights. Technical report. URL https://population.un.org/wup/. 
Vigdor, J. L. 2002. Does gentrification harm the poor? Brookings-Wharton Papers on Urban Affairs, pp. 133-182. doi: 10.1353/urb.2002.0012.

Wardrip, K. 2011. Public Transit's Impact on Housing Costs. Technical Report August, Center for Housing Policy.

Zuk, M., A. H. Bierbaum, K. Chapple, K. Gorska, and A. Loukaitou-Sideris. 2018. Gentrification, displacement, and the role of public investment. Journal of Planning Literature, 33(1):31-44. ISSN 0885-4122. doi: $10.1177 / 0885412217716439$.

Zuk, M. and K. Chapple. 2015. Urban Displacement Project. URL https://www.urbandisplacement. org/.

Zuk, M. and K. Chapple. 2015. Case Studies on Gentrification \& Displacement in the San Francisco Bay Area. Technical report. URL http://www.urbandisplacement.org/sites/ default/files/images/ case_studies_on_gentrification_and_displacement-_full_report.pdf. 